\title{
Risk factors for gestational diabetes mellitus: A prospective case-control study from coastal Karnataka ${ }^{\text {it }}$
}

\author{
Surabhi Mishra ${ }^{\mathrm{a}}$, Avinash Shetty ${ }^{\mathrm{b}}$, Chythra R. Rao ${ }^{\mathrm{b}, *}$, Sathisha Nayak ${ }^{\mathrm{c}}$, Asha Kamath ${ }^{\mathrm{d}}$ \\ ${ }^{a}$ Department of Community Medicine, Himalayan Institute of Medical Sciences (HIMS), Swami Rama Himalayan University (SRHU), Swami Ram Nagar, Jolly Grant, \\ Dehradun, 248016, Uttarakhand, India \\ ${ }^{\mathrm{b}}$ Department of Community Medicine, Kasturba Medical College Manipal, Manipal Academy of Higher Education (MAHE), Manipal, 576104, Karnataka, India \\ ${ }^{\mathrm{c}}$ Department of Obstetrics and Gynaecology, Melaka-Manipal Medical College, Manipal Academy of Higher Education, Dr. TMA Pai Rotary Hospital, Karkala, Karnataka, \\ India \\ ${ }^{\mathrm{d}}$ Department of Data Sciences, Prasanna School of Public Health, Manipal Academy of Higher Education (MAHE), Manipal, Karnataka, India
}

\section{A R T I C L E I N F O}

\section{Keywords:}

Gestational

Diabetes

Case-control studies

Risk factors

Physical activity

\begin{abstract}
A B S T R A C T
Background: Identification of gestational diabetes mellitus (GDM) risk factors is pertinent, for it can be an effective intervention for its prevention. As previous information regarding GDM risk factors from India were mostly descriptive and scarce from coastal Karnataka, a current prospective case-control study was designed to identify GDM risk factors among pregnant women seeking antenatal care.

Methods: A hospital-based prospective matched case-control study was carried among antenatal subjects seeking routine antenatal care at two secondary-level care private hospitals, affiliated to a University Medical College in coastal Karnataka. It comprised of 100 incident GDM cases and 273 frequency-matched controls. Data was collected by personal interviews using a pretested questionnaire. Data was entered and analyzed using Statistical Package for Social Sciences(SPSS), version 15.0.

Results: Risk factors using Carpenter and Coustan criteria and DIPSI criteria were found similar. Pooled data identified following significant GDM risk factors: marital age (25-29 years)(adjusted OR:18.2; 95\% CI:1.9-177.6; p= 0.012), delayed menarche (adjusted OR:11.4; 95\% CI:1.1-124.6; p=0.045), multiparity (adjusted OR:14.1; 95\% CI:1.8-109.8; p=0.011), family history of DM (adjusted OR:66.6; 95\% CI:6.9-645.2; $\mathrm{p}<0.001$ ), high maternal perceived stress (adjusted OR:21.6; 95\% CI:1.9-248.8; $\mathrm{p}=0.014$, less physical activity (adjusted OR:21.0; 95\% CI: 2.8-158.8; $\mathrm{p}=0.003$ ), and low intake of green leafy vegetables (GLV)(adjusted OR:41.7; 95\% CI:3.7-472.4; $\mathrm{p}=0.003$ ). Positive current polyhydramnios and recurrent vaginal infections were also identified as significant risk factors $(\mathrm{p}<0.05)$.

Conclusions: Modifiable risk factors identified were low physical activity, high antenatal perceived stress, multiparity, marital age $\geq 25$ years, and low pre-pregnancy intake of GLV, which were also comparable using two criteria in vogue for GDM diagnosis. Pre-conception advice on healthy lifestyle may prove beneficial.
\end{abstract}

\section{Introduction}

Gestational diabetes mellitus (GDM), defined as carbohydrate intolerance of variable degree with onset or recognition during pregnancy, has been recently identified as a potential risk factor for Type II Diabetes Mellitus (T2DM). ${ }^{1}$ As per International Diabetes Federation (IDF) 2017, one in seven births is affected by GDM. 16.2\% (21.3 million) of live births is to women with hyperglycemia in pregnancy
(HIP). ${ }^{2}$ India, being home to 69.2 million diabetic subjects, has also become the "diabetes capital of the world" harboring around four million women with GDM alone. ${ }^{3}$ Though number of live births affected by HIP has been showing slight increment since 2015, reports of adverse perinatal outcomes due to GDM have been recognized among $86.4 \%$ of $^{\text {cases. }}{ }^{2}$

Various risk factors have been identified as predictors of GDM. In general, they predict the occurrence of T2DM as well. They are

\footnotetext{
Institution where study was conducted: Dr. TMA Pai Rotary Hospital, Karkala, Karnataka (India) and Dr. TMA Pai Hospital, Udupi, Karnataka affiliated to Melaka-Manipal Medical College, Manipal Academy of Higher Education, Karnataka (India).

* Corresponding author. Department of Community Medicine Kasturba Medical College, Manipal Academy of Higher Education, Manipal, 576104, India.

E-mail addresses: surabhimishra42@gmail.com (S. Mishra), avinash.shetty@manipal.edu (A. Shetty), chythra.raj@manipal.edu (C.R. Rao), sathisha.nayak@manipal.edu (S. Nayak), asha.kamath@manipal.edu (A. Kamath).
} 
advanced maternal age, positive family history of T2DM, obesity, and glycosuria. In addition, certain maternal and neonatal outcomes in previous pregnancies have also been found associated with greater likelihood of developing GDM in the present pregnancy. They include positive history of spontaneous abortions, GDM, pregnancy induced hypertension (PIH), polyhydramnios, pre-term labor, caesarian deliveries, unexplained still births, macrosomia, congenital malformations, neonatal complications like respiratory distress syndrome (RDS) and hypoglycemia. ${ }^{4}$ Therefore, to avoid the influence of modifiable factors, their early identification plays an important role.

It has been observed that usual lifestyle modifications or medical interventions offered late in life are of little help as they target only post-primary prevention of overt DM. Today, the need of the hour is to timely identify GDM risk factors so as to prevent subsequent development of overt DM and other long-term complications. ${ }^{5}$ Although Government of India $(\mathrm{GoI})^{6}$ recent initiative to universally screen all Indian pregnant women for GDM has helped in targeting prevention of GDMrelated complications, it does not prevent occurrence of GDM. Prevention of glucose intolerance requires rather a comprehensive approach wherein strategies to prevent GDM risk factors during prepregnancy phase are also addressed. ${ }^{7}$

Amidst differences in diagnosing GDM due to various existing national and international guidelines without any standard protocols for Indian population, Carpenter and Coustan criteria $(1982)^{8}$ was earlier employed as diagnostic criterion by some treating obstetricians. But it was long debated for being a costly procedure associated with poor patient compliance. ${ }^{9}$ It was only after the GoI launch of local national guidelines in 2014, Diabetes in Pregnancy Study Group India (DIPSI) guidelines was adopted nation-wide. ${ }^{6}$ DIPSI guidelines are at an advantage for being not only simple, but also cost-effective and patientfriendly in contrast to previous guidelines. ${ }^{6}$ Diagnosis and management of conditions like GDM in primary care, largely relies on availability of standard guidelines. In this regard, adoption of GoI guidelines for GDM diagnosis and management is largely beneficial for ensuring uniformity and minimizing diagnostic errors.

As information regarding risk factors for GDM was scarce from coastal Karnataka, the current study was designed to identify GDM risk factors among pregnant women seeking antenatal care at secondary care hospitals in coastal district of Karnataka (South India). Existing literature has been mostly descriptive in nature; hence the study additionally employed an analytical design - prospective case control study - with a unique advantage of prospective enrolment of incident cases. Prospective enrolment largely circumvents the risk of recall bias. In addition, it was also postulated to assess similarity in GDM risk factors when either Carpenter and Coustan, or DIPSI criteria was used for diagnosis of GDM.

\section{Methods}

\subsection{Study design and participants}

The present study was carried out at two private hospitals of a coastal district. It is situated along the coastline in the southern part of India, covering a population of 1.18 million and is spread over an area of $3575 \mathrm{~km}^{2}$. As per District Level Household and Facility Survey (DLHS)-4 (2012-13) of the district, $53.4 \%$ of its pregnant women received full antenatal care. ${ }^{10}$ The district has good health indicators including $98.8 \%$ institutional deliveries, of which $68.1 \%$ are delivered in private institutions. ${ }^{10}$

The study population included all pregnant women coming for routine antenatal care to secondary care hospitals. Data was collected over the period of 24 months (2014-2016). Cases included incident GDM subjects coming to antenatal out-patient department (OPD). A pregnant woman newly diagnosed with GDM in her present pregnancy by 3-h, $100 \mathrm{~g}$ oral glucose tolerance test (OGTT) after 20 weeks of gestation using Carpenter and Coustan Criteria at the health care setting was recruited as 'case'. OGTTwas done following a positive 1-h $50 \mathrm{~g}$ glucose challenge test (GCT) exceeding $\geq 140 \mathrm{mg} / \mathrm{dL}$. The next pregnant woman, frequency-matched with period-of-gestation (POG) $( \pm 2$ weeks), identified as non-GDM by 1-h $50 \mathrm{~g}$ GCT value $<140 \mathrm{mg} / \mathrm{dL}$, was included as 'control'. All those pregnant women who had already been diagnosed with diabetes mellitus prior to current pregnancy were excluded from the study. Age as a risk factor for GDM was considered for sample size estimation. Expecting $23.7 \%$ of the cases to be > 25years of age, ${ }^{11}$ and anticipating a difference of at least $15 \%$ in the risk factor profile between the cases and controls to be clinically significant for a power of $80 \%$, at $5 \%$ level of significance and $10 \%$ nonresponse rate, a minimum of 73 cases and 219 controls, frequencymatched with POG, were required to be recruited, with a case-to-control ratio of 1:3.

GDM was diagnosed using Carpenter and Coustan criteria during the initiation of the study. ${ }^{8}$ Subsequently, DIPSI criteria was adopted as a new diagnostic criterion from November 2015 onwards. ${ }^{6}$ It was uniformly adopted by the treating obstetricians at both the study settings by consensus following a departmental review. The data collection was continued to interview the predetermined number of cases and controls as per sample size calculation. But in order to ascertain the similarity between risk factors among cases and controls, an additional 27 cases and 54 POG frequency-matched controls (1:2) were recruited according to the new criteria. The additional number was decided based on the time available for data collection.

Accordingly, the operational definition of both cases and controls was changed as per new DIPSI guidelines. ${ }^{6}$ A pregnant woman newly diagnosed with GDM in her present pregnancy by 2-h $75 \mathrm{~g}$ single venous plasma glucose after 20 weeks of gestation exceeding $\geq 140 \mathrm{mg}$ / $\mathrm{dL}$ (irrespective of the last meal timings) at a health care setting was considered as a 'new case'. The next pregnant women, frequency-matched with POG ( \pm 2 weeks), whose 2 -h $75 \mathrm{~g}$ single venous plasma glucose value was $<140 \mathrm{mg} / \mathrm{dL}$ was included as a 'new control' in 1:2 ratio.

\section{Methodology}

All procedures performed in studies involving human participants were in accordance with the ethical standards of the institutional and/ or national research committee and with the 1964 Helsinki declaration and its later amendments or comparable ethical standards. Institutional ethical committee (IEC:623/2014) approval was obtained prior to initiation of the study and subsequent modification, due to change in the diagnostic criteria and sample size, was duly notified to the ethics committee. Subject information sheet was distributed to all study subjects and written informed consent was obtained from all individual participants included in the study. Newly diagnosed GDM cases were identified from the antenatal OPD. On the same day, POG frequencymatched controls were also identified. Cases and controls fulfilling the inclusion criteria were then interviewed. Data was collected by personal interviews using a pretested questionnaire.

\subsection{Assessment of pre-pregnancy diet}

The pre-pregnancy diet of recruited participants was assessed using the food frequency questionnaire. Intake of food items per week with respect to broad nutrient groups was elicited through dietary recall method.

\subsection{Assessment of socio-economic status}

Socio-economic status (SES) was assessed using modified UdaiPareek Scale. ${ }^{12}$ A score of $<40$ was identified as belonging to low, $40-70$ middle, and $\geq 70$ high SES. ${ }^{12}$ 


\subsection{Assessment of stress}

Assessment of stress was done using a standard questionnaire - the Cohen 10-item Perceived Stress Scale (PSS). ${ }^{13,14}$ Participants were asked to respond to each question on a 5-point Likert scale ranging from zero (never) to four (very often), that indicates how often they have felt or thought a certain way within the past month. Positively-worded items were reverse scored and ratings were summed across all 10 items. Scores so obtained ranged between zero and 40; higher composite scores indicating greater perceived stress, and vice versa. In the present study, the PSS score of $<20$ was graded as low whereas $\geq 20$ was considered as high stress. ${ }^{13,14}$

\subsection{Assessment of physical activity}

Data regarding physical activity was obtained by administrating a standardized questionnaire - the long form of International Physical Activity Questionnaire-long form (IPAQ). ${ }^{15}$ This version of IPAQ assesses physical activity across a comprehensive set of four domains, viz., work, transport, domestic and garden (yard), and leisure time-related physical activities in the last seven days of interview. ${ }^{15}$ Domainspecific sub-scores were then assigned pertaining to each physical activity type. Total score was computed as the summation of duration (in minutes) and frequency (days) for all activities types across all domains. Data so collected were reported in metabolic equivalent-minutes per week (MET-minutes/week), which can be computed by weighing each type of activity by its energy requirements defined in METs. These METs are multiples of resting metabolic rates. MET-minute/week was then computed for each activity as follows: ${ }^{15}$

MET-minutes/week $=$ MET level $\times$ minutes of activity/ day $\times$ days/week.

Total score was calculated for each domain, and then, the overall grand total was estimated. The overall grand total scores so computed were sub-categorized into three levels of physical activity: ${ }^{15}$

1 High: Total physical activity $\geq 3000$ MET-minutes/week

2 Moderate: Total physical activity 600 to $<3000$ MET-minutes/ week

3 Low: Total physical activity $<600$ MET-minutes/week.

Both Cohen-10 item PSS and IPAQ scales were translated from original English version into local Kannada language by two native Kannada speaking medico-social workers independently. Translations and back translations were matched and finalized, pilot tested and validated.

\subsection{Anthropometric measurements}

Anthropometric measurements were taken for all the subjects. Weight was measured using a standard weighing scale (in kgs) kept on a firm horizontal surface, recorded to the nearest $500 \mathrm{~g}$. Height was measured using a measuring tape or stadiometer (in $\mathrm{cms}$ ) to the nearest one $\mathrm{cm}$. Subjects were requested to stand upright barefoot with their back against wall, heels together and looking forward. ${ }^{16}$ Pre-pregnancy body mass index (BMI) was calculated as the ratio of pre-pregnancy weight (kgs) to square of height (metres). ${ }^{16}$ Weight at first antenatal registration in first trimester was considered as pre-pregnancy weight. Weight gain for the current pregnancy was computed by subtracting 'pre-pregnancy weight' from 'current weight'.

\subsection{Statistical analysis}

Data was entered and analyzed using Statistical Package for Social Sciences (SPSS), version 15. The results are expressed as percentages and proportions for categorical variables. Comparison of the risk factors among cases and controls was done using univariate logistic regression,

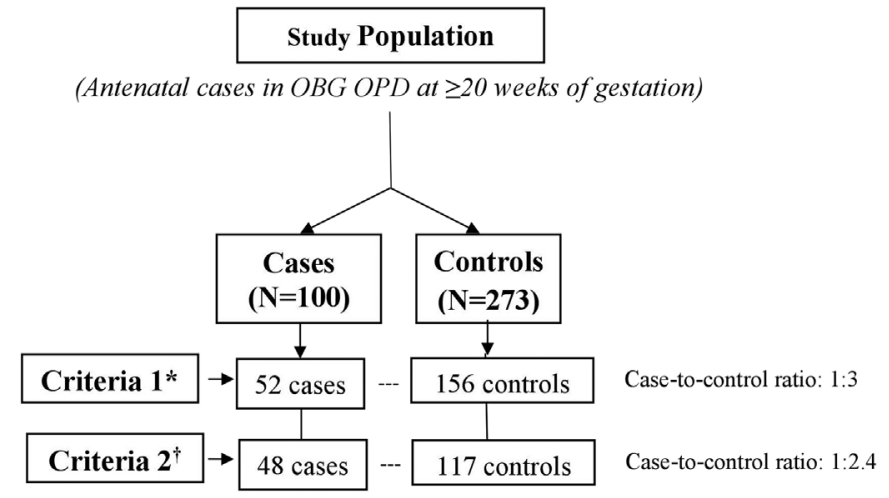

* Criteria 1: Carpenter \& Coustan Criteria ${ }^{8}$ $\dagger$ Criteria 2: DIPSI guidelines ${ }^{6}$

Fig. 1. Recruitment of study subjects.

and odds ratio (OR) with $95 \%$ confidence interval (CI) was calculated to study the association between the different variables. Variables found to have $\mathrm{p}<0.20$ were used for multiple logistic regression to identify the independent risk factors for GDM and adjusted odds ratio with $95 \%$ CI was computed. A p $<0.05$ was considered to be statistically significant.

\section{Results}

In the present study, total 100 GDM cases and 273 POG frequencymatched controls were recruited at an overall case-to-control ratio of 1:2.7 (Fig. 1). Among the total, 52 cases and 156 controls were recruited based on Carpenter and Coustan criteria (case-to-control ratio of 1:3). Following change in the diagnostic criteria, remaining 48 cases and 117 controls were enrolled based on DIPSI guidelines (case-tocontrol ratio of 1:2.4). The mean ( \pm SD) POG of diagnosis for cases was 27 weeks 2 days ( \pm 5 weeks 2 days) while for controls, POG was 26 weeks 2 days ( \pm 4 weeks 2 days).

The baseline socio-demographic characteristics of the study subjects (Table 1) showed higher odds of GDM among those aged $\geq 30$ years (Crude OR 17.3, p < 0.001). Age at menarche was earlier among controls as against cases $(\mathrm{p}<0.001)$. Majority of the Christians were older than Hindus, thus the odds of GDM was higher among Christians compared to Hindus (Crude OR 4.7, p = 0.002). Odds of GDM cases being overweight ( $\geq 60 \mathrm{kgs}$ ) in their pre-pregnancy period was higher than controls (Crude OR 2.6, $\mathrm{p}=0.001$ ). Odds for high stress (Crude OR 12.9), and low-to-moderate physical activity (Crude OR 5.9) among GDM cases was also higher than controls ( $\mathrm{p}<0.001$ ).Pertaining to obstetric details of current pregnancy (Table 2), $85.3 \%$ of the controls were primigravida while $66 \%$ of cases were multigravida ( $p<0.001$ ). Odds of GDM was higher for multiparity compared to nulliparous women (Crude OR 11.5, $\mathrm{p}<0.001$ ). $58.8 \%$ of the cases had higher weight gain ( $\geq 7 \mathrm{kgs}$ ) compared to $23.7 \%$ of the controls (Crude OR 4.5 , $\mathrm{p}<0.001$ ). Polyhydramnios was present among $61 \%$ of the cases in contrast to only five controls ( $\mathrm{p}<0.001$ ).

In past obstetric history, among the multigravid subjects, $34.8 \%$ of the cases $(n=23)$ had past history of GDM compared to $2.5 \%$ of controls $(\mathrm{p}=0.004)$. Among multigravida, $18.2 \%(\mathrm{n}=12)$ had recurrent vaginal infections, $31.8 \%(\mathrm{n}=21)$ polyhydramnios, and $13.6 \%$ $(\mathrm{n}=9$ ) had pre-term deliveries in the past whereas none of the multigravid controls reported these events. Total 86 births were reported in the past. Information regarding birth weight was available only for 81 babies. Odds of GDM was higher among those who gave birth to macrosomic babies ( $\geq 3.5 \mathrm{kgs}$ ) more than once (36.5\%) than controls $(3.4 \%)(\mathrm{p}=0.009)$. 
Table 1

Baseline characteristics of study subjects.

\begin{tabular}{|c|c|c|c|c|}
\hline Variables & Cases(N = 100); $\mathrm{n}(\%)$ & Controls( $\mathrm{N}=273) ; \mathrm{n}(\%)$ & Crude Odds Ratio(95\% CI) & p-value \\
\hline \multicolumn{5}{|l|}{ Age (years) } \\
\hline$\leq 25$ & $16(16.0)$ & $117(42.9)$ & 1.0 & \\
\hline $26-29$ & $25(25.0)$ & $131(48.0)$ & $1.4(0.7-2.7)$ & 0.333 \\
\hline$\geq 30$ & $59(59.0)$ & $25(9.1)$ & $17.3(8.6-34.8)$ & $<0.001$ \\
\hline \multicolumn{5}{|l|}{ Age at marriage (years) } \\
\hline$<25$ & $30(30.0)$ & $166(60.8)$ & 1.0 & \\
\hline $25-29$ & $48(48.0)$ & $98(35.9)$ & $2.7(1.6-4.6)$ & $<0.001$ \\
\hline$\geq 30$ & $22(22.0)$ & $9(3.3)$ & $13.5(5.7-32.2)$ & $<0.001$ \\
\hline \multicolumn{5}{|c|}{ Duration of marriage (months) } \\
\hline$<12$ & $20(20.0)$ & $130(47.6)$ & 1.0 & \\
\hline $12-35$ & $22(22.0)$ & $86(31.5)$ & $1.7(0.9-3.2)$ & 0.133 \\
\hline $36-59$ & $31(31.0)$ & $36(13.2)$ & $5.6(2.9-11.0)$ & $<0.001$ \\
\hline$\geq 60$ & $27(27.0)$ & 21(7.7) & $8.4(4.0-17.5)$ & $<0.001$ \\
\hline \multicolumn{5}{|c|}{ Age at menarche (years) ${ }^{\S}$} \\
\hline 11 & $14(14.0)$ & $91(33.3)$ & 1.0 & \\
\hline 12 & $23(23.0)$ & $140(51.3)$ & $1.1(0.5-2.2)$ & 0.857 \\
\hline 13 & $39(39.0)$ & $28(10.3)$ & $9.1(4.3-19.0)$ & $<0.001$ \\
\hline$\geq 14$ & $24(24.0)$ & $14(5.1)$ & $11.1(4.7-26.5)$ & $<0.001$ \\
\hline \multicolumn{5}{|l|}{ Religion } \\
\hline Hindu & $82(82.0)$ & 245(89.7) & 1.0 & \\
\hline Muslim & $7(7.7)$ & $21(7.7)$ & $1.0(0.4-2.4)$ & 0.993 \\
\hline Christian & $11(11.0)$ & $7(2.6)$ & $4.7(1.8-12.5)$ & 0.002 \\
\hline \multicolumn{5}{|l|}{ Education } \\
\hline$<$ Class 7 th $^{\dagger}$ & $8(8.0)$ & $18(6.6)$ & 1.0 & \\
\hline Class 8th-12th & $67(67.0)$ & $221(81.0)$ & $0.7(0.3-1.6)$ & 0.4 \\
\hline Graduation \& above & $25(25.0)$ & $34(12.4)$ & $1.7(0.6-4.4)$ & 0.392 \\
\hline \multicolumn{5}{|l|}{ Occupation } \\
\hline Homemakers & $89(89.0)$ & $259(94.9)$ & 1.0 & \\
\hline Working & $11(11.0)$ & $14(5.1)$ & $2.3(1.0-5.2)$ & 0.05 \\
\hline \multicolumn{5}{|l|}{ SES Class } \\
\hline Low & $8(8.0)$ & 49(17.9) & 1.0 & \\
\hline Middle \& High & $92(92.0)$ & $224(82.1)$ & $2.5(1.1-5.5)$ & 0.021 \\
\hline \multicolumn{5}{|l|}{ Stature $(\mathrm{cms})$} \\
\hline$<150$ & $8(8.0)$ & $38(13.9)$ & 1.0 & \\
\hline $150-159.9$ & $69(69.0)$ & $183(67.0)$ & $1.8(0.8-4.0)$ & 0.159 \\
\hline$\geq 160$ & $23(23.0)$ & $52(19.1)$ & $2.1(0.8-5.2)$ & 0.109 \\
\hline \multicolumn{5}{|c|}{ Pre-pregnancy weight $(\mathrm{kgs})^{¥}$} \\
\hline$<50$ & $29(29.0)$ & $106(44.0)$ & 1.0 & \\
\hline $50-60$ & $31(31.0)$ & $79(32.8)$ & $1.4(0.8-2.6)$ & 0.226 \\
\hline$\geq 60$ & $40(40.0)$ & $56(23.2)$ & $2.6(1.5-4.7)$ & 0.001 \\
\hline \multicolumn{5}{|c|}{ Pre-pregnancy BMI $\left(\mathrm{kg} / \mathrm{m}^{2}\right)^{¥}$} \\
\hline$<25$ & $67(67.0)$ & $200(83.0)$ & 1.0 & \\
\hline$\geq 25$ & $33(33.0)$ & $41(17.0)$ & $2.4(1.4-4.1)$ & 0.001 \\
\hline \multicolumn{5}{|c|}{ Cohen Perceived Stress Scale Score } \\
\hline Low Stress & $47(47.0)$ & 251(91.9) & 1.0 & \\
\hline High Stress & $53(53.0)$ & $22(8.1)$ & $12.9(7.2-23.1)$ & $<0.001$ \\
\hline \multicolumn{5}{|c|}{ IPAQ Score (MET-minutes/week) } \\
\hline High & $43(43.0)$ & 223(81.7) & 1.0 & \\
\hline Low-to-moderate & $57(57.0)$ & $50(18.3)$ & $5.9(3.6-9.8)$ & $<0.001$ \\
\hline
\end{tabular}

§None of the subject had attained menarche $<11$ years of age.

†One subject in the control was illiterate.

$¥ B M I$ could not be computed for 32 subjects as they did not remember their pre-pregnancy weight.

Abbreviations: BMI: Body Mass Index; IPAQ: International Physical Activity Questionnaire.

Pertaining to family history, exposure rates for both maternal and paternal history of DM was significantly more among cases ( $p<0.001$ ). Information regarding pre-pregnancy diet showed higher odds of GDM for consumption of cereals $\geq 20$ times per week ( $\mathrm{p}<0.001$ ). Controls proportionately consumed higher amounts of protective foods (green leafy vegetables, vegetables, fruits, and milk) compared to cases ( $\mathrm{p}<0.001$ ). Odds of GDM cases consuming nonvegetarian food $\geq 4$ times a week (56\%) was 1.7 times higher than controls $(p=0.025)$. Intake of sweets was similar among cases and controls $(\mathrm{p}=0.509)$.

Due to switch of diagnostic criteria from Carpenter and Coustan to DIPSI guidelines during the study period, the risk factor profile was compared between the two diagnostic criteria (Table 3). The association of risk factors for GDM using either criteria was found to be similar. Following risk factors were identified in common; age $\geq 30$ years, age at marriage $\geq 30$ years, age at menarche $\geq 1$ years, multiparity, family history of DM, high perceived stress levels, less physical activity, less protective foods in pre-pregnancy diet.

As risk factors were similar between two criteria, multivariate analysis was done for pooled data (Table 4). Modifiable risk factors identified were age at marriage (25-29 years), multiparity, high stress, less physical activity, and low intake of green leafy vegetables. The key non-modifiable risk factors identified were maternal and paternal history of DM, and age at menarche $\geq 14$ years.

\section{Discussion}

GDM, defined as carbohydrate intolerance of variable degree with onset or recognition during pregnancy, has been identified as precursor for T2DM. To combat rising T2DM prevalence, timely identification of GDM risk factors during prenatal period will serve as a primordial prevention tool. 
Table 2

Determinants of GDM pertaining to present obstetric details.

\begin{tabular}{|c|c|c|c|c|}
\hline Variables & $\begin{array}{l}\operatorname{Cases}(\mathrm{N}=100) ; \mathrm{n} \\
(\%)\end{array}$ & $\begin{array}{l}\text { Controls } \\
(\mathrm{N}=273) ; \mathrm{n} \\
(\%)\end{array}$ & $\begin{array}{l}\text { Crude Odds } \\
\text { Ratio (95\% } \\
\text { CI) }\end{array}$ & $\mathrm{p}$-value \\
\hline \multicolumn{5}{|l|}{ Gravida } \\
\hline Primigravida & $34(34.0)$ & $233(85.3)$ & 1.0 & \\
\hline Multigravida & $66(66.0)$ & $40(14.7)$ & $\begin{array}{l}11.3(6.6- \\
19.3)\end{array}$ & $<0.001$ \\
\hline \multicolumn{5}{|l|}{ Parity } \\
\hline Nulliparous & $35(35.0)$ & $235(86.1)$ & 1.0 & \\
\hline Multiparous & $65(65.0)$ & $38(13.9)$ & $\begin{array}{l}11.5(6.7- \\
19.6)\end{array}$ & $<0.001$ \\
\hline \multicolumn{5}{|c|}{ Weight gain $(\mathrm{kgs})^{\S}$} \\
\hline$<7$ & $42(42.0)$ & $184(76.3)$ & 1.0 & \\
\hline$\geq 7$ & $58(58.0)$ & $57(23.7)$ & $4.5(2.7-7.3)$ & $<0.001$ \\
\hline
\end{tabular}

$\S_{32}$ subjects among controls did not remember their pre-pregnancy weight. Thus, results depicted are provided for 100 cases and 241 controls.

High GDM risk among those aged $\geq 30$ years identified in the present study were supported by other prospective cohort studies carried out by Sharma et al. and Leng et al. using WHO and IADPSG-WHO criteria respectively ${ }^{17,18}$; although studies carried out in northern India using DIPSI criteria found high risk among $\geq 25$ years women. ${ }^{19,20}$
Marital age $>25$ years, identified higher odds for GDM in the present study; but this was in contrast to the study done in Oman wherein significant relationship was observed between GDM incidence and marital age $<18$ years ( $\mathrm{p}<0.010$; likelihood ratio $=43.9) \cdot{ }^{21}$ Another study carried out by Varghese et al. also showed increased GDM prevalence with duration of marriage $>3$ years. $^{22}$ Older age at child bearing increases GDM risk indirectly and this is reflected through delayed age at marriage and longer duration of married life.

GDM risk of with delayed menarche ( $\geq 14$ years) noted in the present study was substantiated by another case-control study carried out in Babol (Mazandaran) ${ }^{23}$ where menarche $\geq 12$ years was identified as a risk factor. Hormonal, genetic, environmental factors also play a role in menarche onset and subsequentGDM risk.

Obesity has long been associated with high GDM and T2DM risk. This has also been documented by various prospective Indian cohort studies which have reported a high GDM prevalence among subjects with pre-pregnancy BMI $\geq 25 \mathrm{~kg} / \mathrm{m}^{2}$ irrespective of the diagnostic criteria used. ${ }^{17,20}$ This is in accordance to present study findings; while studies carried out in Odisha found high GDM prevalence among BMI $\geq 30 \mathrm{~kg} / \mathrm{m}^{2} .{ }^{24}$

Traditional risk factors like stress and physical inactivity incriminated for T2DM have also been proposed as risk factors for GDM.

Table 3

Comparison of significant determinants of GDM with Carpenter and Coustan and DIPSI Criteria.

\begin{tabular}{|c|c|c|c|c|c|c|}
\hline \multirow[t]{4}{*}{ Variables } & \multicolumn{4}{|c|}{ Carpenter \& Coustan Criteria } & \multicolumn{2}{|c|}{ DIPSI criteria } \\
\hline & Cases & Controls & Crude OR (95\% CI); p-value & Cases & Controls & Crude OR (95\% CI); p-value \\
\hline & $\mathrm{N}=52$ & $\mathrm{~N}=156$ & & $\mathrm{~N}=48$ & $\mathrm{~N}=117$ & \\
\hline & $\mathrm{n}(\%)$ & $\mathrm{n}(\%)$ & & $\mathrm{n}(\%)$ & $\mathrm{n}(\%)$ & \\
\hline \multicolumn{7}{|l|}{ Age(years) } \\
\hline$\leq 25$ & $10(19.2)$ & $70(44.9)$ & 1.0 & $6(12.5)$ & $47(40.2)$ & 1.0 \\
\hline $26-29$ & $12(23.1)$ & $67(42.9)$ & $1.3(0.5-3.1) ; 0.624$ & $13(27.1)$ & $64(54.7)$ & $1.6(0.6-4.5) ; 0.0381$ \\
\hline$\geq 30$ & $30(57.7)$ & $19(12.2)$ & $11.1(4.6-26.6) ;<0.001$ & $29(60.4)$ & $6(5.1)$ & $37.9(11.1-128.6) ;<0.001$ \\
\hline \multicolumn{7}{|c|}{ Age at marriage (years) } \\
\hline$<25$ & $21(40.4)$ & 104(66.7) & 1.0 & $9(18.7)$ & $62(53.0)$ & 1.0 \\
\hline $25-29$ & $16(30.8)$ & $45(28.8)$ & $1.8(0.8-3.7) ; 0.133$ & $32(66.7)$ & $53(45.3)$ & $4.2(1.8-9.5) ; 0.001$ \\
\hline$\geq 30$ & $15(28.8)$ & $7(4.5)$ & $10.6(3.9-29.2) ;<0.001$ & $7(14.6)$ & $2(1.7)$ & $24.1(4.3-134.6) ;<0.001$ \\
\hline \multicolumn{7}{|c|}{ Age at menarche (years) } \\
\hline$\leq 11$ & $9(17.3)$ & $49(31.4)$ & 1.0 & $5(10.4)$ & $42(35.9)$ & 1.0 \\
\hline 12 & $10(19.2)$ & $86(55.1)$ & $0.6(0.2-1.7) ; 0.0354$ & $13(27.1)$ & $54(46.1)$ & $2.0(0.7-6.1) ; 0.213$ \\
\hline 13 & $17(32.7)$ & $12(7.7)$ & $7.7(2.8-21.5) ;<0.001$ & $22(45.8)$ & $16(13.7)$ & $11.6(3.7-35.7) ;<0.001$ \\
\hline$\geq 14$ & $16(30.8)$ & $9(5.8)$ & $9.7(3.3-28.6) ;<0.001$ & $8(16.7)$ & $5(4.3)$ & $13.4(3.1-57.4) ;<0.001$ \\
\hline \multicolumn{7}{|l|}{ Parity } \\
\hline Nulliparous & $20(38.4)$ & $124(79.5)$ & 1.0 & $15(31.3)$ & $111(94.9)$ & 1.0 \\
\hline 1 & $29(55.8)$ & $29(18.6)$ & 6.2(3.1-12.5); 0.001 & $30(62.5)$ & $6(5.1)$ & $37.0(13.2-103.5) ;<0.001$ \\
\hline$\geq 2$ & $3(5.8)$ & $3(1.9)$ & $6.2(1.2-32.9) ; 0.032$ & $3(6.2)$ & $0(0.0)$ & $1.91(<0.001) ; 0.999$ \\
\hline \multicolumn{7}{|c|}{$\mathrm{H} / \mathrm{o} \mathrm{DM}$ in both parents } \\
\hline No & $12(23.1)$ & $128(82.1)$ & 1.0 & $17(35.4)$ & $107(91.5)$ & 1.0 \\
\hline Yes & $40(76.9)$ & $28(17.9)$ & 15.2(7.1-32.7); < 0.001 & $31(64.6)$ & $10(8.5)$ & $19.5(8.1-46.9) ;<0.001$ \\
\hline \multicolumn{7}{|l|}{ Cohen Stress Scale } \\
\hline Low Stress & $18(34.6)$ & $136(87.2)$ & 1.0 & $29(60.4)$ & $115(98.3)$ & 1.0 \\
\hline High Stress & $34(65.4)$ & $20(12.8)$ & $12.8(6.1-26.9) ;<0.001$ & 19(39.6) & $2(1.7)$ & $37.7(8.3-171.0) ;<0.001$ \\
\hline \multicolumn{7}{|c|}{ IPAQ (MET-minutes/week) } \\
\hline High & $24(46.2)$ & $140(89.7)$ & 1.0 & 19(39.6) & $83(70.9)$ & 1.0 \\
\hline Low-to-moderate & $28(53.8)$ & $16(10.3)$ & $10.2(4.8-21.6) ;<0.001$ & $29(60.4)$ & $34(29.1)$ & $3.7(1.8-7.5) ;<0.001$ \\
\hline \multicolumn{7}{|c|}{ Pulses intake per week } \\
\hline$\geq 2$ & $16(30.8)$ & $34(21.8)$ & 1.0 & $22(45.8)$ & $31(26.5)$ & 1.0 \\
\hline$<2$ & $36(69.2)$ & $122(78.2)$ & $0.6(0.3-1.3) ; 0.192$ & $26(54.2)$ & $86(73.5)$ & $0.4(0.2-0.9) ; 0.017$ \\
\hline \multicolumn{7}{|l|}{ GLV intake/week } \\
\hline$\geq 1$ & $11(21.2)$ & 61(39.1) & 1.0 & $9(18.8)$ & $61(52.1)$ & 1.0 \\
\hline$<1$ & $41(78.8)$ & $95(60.9)$ & 2.4(1.1-5.0); 0.021 & $39(81.2)$ & $56(47.9)$ & $4.7(2.1-10.6) ;<0.001$ \\
\hline
\end{tabular}

Abbreviations.

DM: Diabetes Mellitus.

GLV: Green Leafy Vegetables.

H/o: History of

IPAQ: International Physical Activity Questionnaire.

MET: Metabolic Equivalent. 
Table 4

Multivariate logistic regression analysis for association of significant determinants with GDM.

\begin{tabular}{|c|c|c|}
\hline Variables & Crude OR (95\% CI); p-value & Adjusted OR (95\% CI); p-value \\
\hline \multicolumn{3}{|l|}{ Age (years) } \\
\hline$\leq 25$ & 1.0 & 1.0 \\
\hline $26-29$ & $1.4(0.7-2.7) ; 0.333$ & $0.09(0.007-1.1) ; 0.059$ \\
\hline$\geq 30$ & $17.3(8.6-34.8) ;<0.001$ & $1.2(0.07-20.9) ; 0.913$ \\
\hline \multicolumn{3}{|c|}{ Age at marriage (years) } \\
\hline$<25$ & 1.0 & 1.0 \\
\hline $25-29$ & $2.7(1.6-4.6) ;<0.001$ & $18.2(1.9-177.6) ; 0.012$ \\
\hline$\geq 30$ & $13.5(5.7-32.2) ;<0.001$ & $3.5(0.2-69.8) ; 0.407$ \\
\hline \multicolumn{3}{|c|}{ Age at menarche (years) } \\
\hline 11 & 1.0 & 1.0 \\
\hline 12 & $1.1(0.5-2.2) ; 0.857$ & $0.1(0.01-0.9) ; 0.041$ \\
\hline 13 & $9.1(4.3-19.0) ;<0.001$ & $0.7(0.06-7.8) ; 0.773$ \\
\hline$\geq 14$ & $11.1(4.7-26.5) ;<0.001$ & $11.4(1.1-124.6) ; 0.045$ \\
\hline \multicolumn{3}{|l|}{ Parity } \\
\hline Nulliparous & 1.0 & 1.0 \\
\hline Multiparous & $11.5(6.7-19.6) ;<0.001$ & $14.1(1.8-109.8) ; 0.011$ \\
\hline \multicolumn{3}{|c|}{$\mathrm{H} / \mathrm{o} \mathrm{DM}$ in both parents } \\
\hline No & 1.0 & 1.0 \\
\hline Yes & $15.1(8.7-26.3) ;<0.001$ & $66.6(6.9-645.2) ;<0.001$ \\
\hline \multicolumn{3}{|c|}{ Cohen Perceived Stress Scale Score } \\
\hline Low Stress & 1.0 & 1.0 \\
\hline High Stress & $12.9(7.2-23.1) ;<0.001$ & $21.6(1.9-248.8) ; 0.014$ \\
\hline \multicolumn{3}{|c|}{ IPAQ score (MET-minutes/week) } \\
\hline High & 1.0 & 1.0 \\
\hline $\begin{array}{l}\text { Low-to- } \\
\text { moderate }\end{array}$ & $5.9(3.6-9.8) ;<0.001$ & $21.0(2.8-158.8) ; 0.003$ \\
\hline \multicolumn{3}{|c|}{ Frequency of Pulses intake per week } \\
\hline$\geq 2$ & 1.0 & 1.0 \\
\hline$<2$ & $0.5(0.3-0.8) ; 0.007$ & $1.04(0.006-0.3) ; 0.002$ \\
\hline \multicolumn{3}{|c|}{ Frequency of GLV intake per week } \\
\hline$\geq 1$ & 1.0 & 1.0 \\
\hline$<1$ & $3.2(1.9-5.6) ;<0.001$ & $41.7(3.7-472.4) ; 0.003$ \\
\hline
\end{tabular}

Abbreviations.

DM: Diabetes Mellitus.

GLV: Green Leafy Vegetables.

H/o: History of.

IPAQ: International Physical Activity Questionnaire.

MET: Metabolic Equivalent.

A prospective cohort study from Western Massachusetts identified increased stress levels from early-to-mid-pregnancy as a risk factor for GDM, concurring with present study findings. ${ }^{25}$ Risk associated with physical inactivity prior or during early pregnancy has been reported by Harizopoulou et al. (Greek-version of IPAQ), similar to the present study. $^{26}$

Multigravid status is a proven risk factor of GDM. ${ }^{19}$ Risk of GDM with weight gain of $>7 \mathrm{kgs}$ in the present pregnancy was supported by a study done in Rohtak, Haryana. ${ }^{11}$ Cohort studies from Northern China also found higher GDM prevalence among subjects with greater weight gain from pre-pregnancy to GCT testing. ${ }^{26}$ Studies carried out by Dahiya et al., ${ }^{19}$ and Nanda et al. ${ }^{24}$ have reported polyhydramnios, vaginal infections and pre-term labor to be associated more with GDM subjects, comparable to the present study findings. Positive association between GDM, glycosuria and proteinuria has also been reported in literature. ${ }^{27}$

Hospital-based prospective studies carried out in different parts of India identified past history of GDM, PIH, abortions, and caesarian sections to be more likely among GDM subjects. ${ }^{27}$ Positive associations between macrosomia and GDM irrespective of study design and diagnostic criteria has been well established, ${ }^{24}$ which was in line with the present study findings.

Significant association between GDM and family history of DM have been reported by multiple Indian studies. ${ }^{11,20,24}$ Arora GP et al., ${ }^{28}$ have reported high prevalence of GDM among subjects consuming high calorie diet especially non-vegetarian diet similar to the present study. Lesser consumption of protective foods is a known risk factor for T2DM and GDM risk factor profile which was similar, to the findings of the present study too.

The key objective of the study was to identify risk factors in coastal/ seaside area. The unique features of this study population are high literacy rates, availability and ease of access to health facilities, universal utilization of antenatal care services and $100 \%$ institutional deliveries. Although it would have been ideal to highlight these variables, the differences are underscored as these characteristics are shared uniformly between cases and controls. Hence, these features have not been identified in the analysis.

Thus to conclude, the key risk factors for GDM were maternal and paternal history of DM, age at menarche $\geq 14$ years, age at marriage (25-29years), multiparity, high perceived stress, less physical activity, and low intake of green leafy vegetables. Prospective enrolment of GDM cases in 1:3 case-to-control ratio, in a hospital setting is the main highlight of the study. Change of diagnostic criteria during the study course, a possible limitation in any prospective design; indirectly helped in paralleling the two criteria with respect to risk factors and confirmed no difference between diagnostic criteria. Non-uniformity in GDM diagnostic criteria, across centres and geographical areas makes comparisons difficult. Eliciting dietary information during a single interview has been another limiting factor. Furthermore, hospital-based data collection limits the generalizability of the study findings. But community-based identification of GDM cases is a difficult task, due to varying time periods of diagnosis and multitude of tests and varying diagnostic criteria in practice. Thus, this hospital based approach was most feasible and pragmatic in a region where institutional antenatal care is universal; and hence the findings reflect the population scenario closely.

\section{Disclaimer}

The views expressed in the submitted article belong to the authors and not an official position of the institution. The manuscript has been read and approved by all the authors. The requirements for authorship have been met, and each author believes that the manuscript represents honest work.

\section{Source of support}

This research did not receive any specific grant from funding agencies in the public, commercial, or not-for-profit sectors.

\section{Presentation at a meeting}

Nil.

\section{CRediT authorship contribution statement}

Surabhi Mishra: Data curation, Formal analysis, Investigation, Methodology, Project administration, Resources, Software, Supervision, Validation, Visualization, Writing - original draft, Writing - review \& editing. Avinash Shetty: Conceptualization, Data curation, Formal analysis, Methodology, Project administration, Resources, Software, Supervision, Validation, Visualization, Writing - original draft, Writing review \& editing. Chythra R. Rao: Conceptualization, Data curation, Formal analysis, Methodology, Project administration, Resources, Software, Supervision, Validation, Visualization, Writing - original draft, Writing - review \& editing. Sathisha Nayak: Conceptualization, Methodology, Project administration, Resources, Supervision, Validation, Writing - review \& editing. Asha Kamath: Conceptualization, Data curation, Formal analysis, Methodology, Project administration, Resources, Software, Validation, Writing - review \& editing. 


\section{Declaration of competing interest}

Nil.

\section{References}

1. Dyck R, Klomp H, Tan LK, Turnell RW, Boctor MA. A comparison of rates, risk factors, and outcomes of gestational diabetes between aboriginal and non-aboriginal women in the Saskatoon health district. Diabetes Care. 2002;25(3):487-493.

2. International Diabetes Federation (IDF). Diabetes Atlas. eighth ed. Brussels, Belgium: International Diabetes Federation; 2017.

3. International Diabetes Federation. Gestational diabetes. . Available from: URL: http://www.idf.org/node/26045, Accessed date: 8 April 2019 Accessed.

4. Zhang C, Ning Y. Effect of dietary and lifestyle factors on the risk of gestational diabetes: review of epidemiologic evidence. J. Am. Soc. Nephrol.Nutr. 2011;94(6 Suppl):1975S-1979S. https://doi.org/10.3945/ajcn.110.001032.

5. Tuomilehto J. Nonpharmacologic therapy and exercise in the prevention of type 2 diabetes. Diabetes Care. 2009;32(Suppl. 2):S189-S193.

6. Government of India. Maternal and Health Division. National Guidelines for Diagnosis and Management of Gestational Diabetes Mellitus: Ministry of Health \& Family Welfare. New Delhi: New Concept Information Systems Ltd; 2014 December:69p.

7. Mishra S, Rao CR, Bhadoria AS, Mohanty S, Kishore S, Chaudhary AS. Life-cycle approach for prevention of gestational diabetes mellitus. Clin. Epidemiol. Clin. Health. 2019;7(3):418-423. https://doi.org/10.1016/j.cegh.2018.11.005 Available at: https://cegh.net/action/showPdf?pii = S2213-3984\%2818\%2930204-5.

8. Carpenter MW, Coustan DR. Criteria for screening tests for gestational diabetes. Am J Obstet Gynecol. 1982;144:768-773.

9. Mishra S, Rao CR, Shetty A. Trends in the diagnosis of gestational diabetes mellitus. Sci Tech Rep. 2016. https://doi.org/10.1155/2016/5489015 Article ID: 5489015

10. Government of India. District Level Household and Facility Survey - 4. District Fact Sheet: Udupi (2012-13). Ministry of Health \& Family Welfare Mumbai: International Institute for Population Sciences; 2012. (updated 2013). Available from: URL. https://nrhmmis.nic.in/DLHS4/State\%20and\%20District\%20Factsheets/Karnataka/ District\%20Factsheets/Udupi.pdf, Accessed date: 15 April 2019 Accessed.

11. Rajput R, Yadav Y, Nanda S, Rajput M, et al. Prevalence of gestational diabetes mellitus \& associated risk factors at a tertiary care hospital in Haryana. Indian J Med Res. 2013;137(4):728-733.

12. Pareek U, Trivedi G. Reliability and validity of socio-economic scales. Indian J Appl Psychol. 1964;1:34-40.

13. Cohen S, Kamarck T, Mermelstein R. A global measure of perceived stress. J Health Soc Behav. 1983;24(4):385-396.

14. Scoring for cohen perceived stress scale. . Available from: URL: http://podcast.uctv.
tv/webdocuments/COHEN-PERCEIVED-STRESS-Scale.pdf, Accessed date: 10 April 2019 Accessed.

15. International Physical Activity Questionnaire. Guidelines for Data Processing and Analysis of the International Physical Activity Questionnaire (IPAQ) - Short and Long Forms. November 2005; November 2005. Available from: URL:https://sites.google.com/ site/theipaq/scoring-protocol , Accessed date: 10 April 2019 Accessed.

16. World Health Organization. Waist Circumference and Waist-Hip Ratio. Report of a WHO Expert Consultation. Geneva. 8-11 December 2008. Geneva, Switzerland: World Health Organization; 2011.

17. Sharma A, Gupta M, Agarwal A. Comparison of diagnostic accuracy of two one step procedures for screening of gestational diabetes mellitus. Int. J. Reprod. Contracep. Obstetrics. Gynecol. 2015;4(1):81-85.

18. Leng J, Shao P, Zhang C, et al. Prevalence of gestational diabetes mellitus and its risk factors in Chinese pregnant women: a prospective population-based study in Tianjin, China. PloS One. 2015;10(3):e0121029https://doi.org/10.1374/journal.pone. 0121029.

19. Dahiya K, Sahu J, Dahiya A. Maternal and fetal outcome in gestational diabetes mellitus-a study at tertiary health centre in northern India. Open Access Library Journal. 2014;1(3):1-5. https://doi.org/10.4236/oalib.1100500.

20. Kalra P, Kachhwaha CP, Singh HV. Prevalence of gestational diabetes mellitus and its outcome in western Rajasthan. Ind. J. Endocrinol. Metabol. 2013;17(4):677-680.

21. Chitme HR, Al Shibli SAS, Al-Shamiry RM. Risk factors and plasma glucose profile of gestational diabetes in Omani women. Oman Med J. 2016;31(5):370-377.

22. Varghese R, Thomas B, Hail MA, et al. The prevalence, risk factors, maternal and fetal outcomes in gestational diabetes mellitus. Int J Drug Dev Res. 2012;4(3):356-368.

23. Barat S, Bouzari Z, Yazdani S, Moslemi R, Hajian-Tilaki K. History of menstrual disorders associated with gestational diabetes mellitus. Caspian J. Reprod. Med. 2016;2(1):27-31.

24. Nanda SS, Dash K, Dash S, Misra S, Das S, et al. Screening of gestational diabetes mellitus with 75 gms OGTT and its effects on feto-maternal outcome. Scholars J Appl Med Sci. 2014;2(1C):340-344.

25. Silveira ML, Whitcomb BW, Pekow P, et al. Perceived psychosocial stress and glucose intolerance among pregnant Hispanic women. Diabetes Metabol. 2014;40(6):466-475. https://doi.org/10.1016/j.diabet.2014.05.002.

26. Harizopoulou VC, Kritikos A, Papanikolaou Z, et al. Maternal physical activity before and during early pregnancy as a risk factor for gestational diabetes mellitus. Acta Diabetol. 2010;47(Suppl 1):S83-S89. https://doi.org/10.1007/s00592-009-0136-1.

27. Garshasbi A, Faghihzadeh S, Naghizadeh MM, Ghavam M, et al. Prevalence and risk factor for gestational diabetes mellitus in tehran. $J$ Fam Reprod Health. 2008;2(2):75-80.

28. Arora GP, Thaman RG, Prasad RB, et al. Prevalence and risk factors of gestational diabetes in Punjab, North India: results from a population screening program. Eur $J$ Endocrinol. 2015;173(2):257-267. 